\title{
Analysis of Carbon Emissions of Prefabricated Buildings from the Views of Energy Conservation and Emission Reduction
}

\author{
Weidong Ma*, Dacheng Sun*†, Yongsheng Deng**, Xianyun Meng** and Mi Li** \\ *Henan Huaxia Construction Management Co. Ltd., Zhengzhou 450053, China \\ **Zhumadian Cigarette Factory of China Tobacco Henna Industrial Co, Ltd., Zhumadian 463000, China \\ †Corresponding author: Dacheng Sun; zzsdz1977@ outlook.com
}

Nat. Env. \& Poll. Tech.

Website: www.neptjournal.com

Received: 23-07-2020

Revised: $15-11-2020$

Accepted: $14-12-2020$

Key Words:

Prefabricated buildings

Carbon emission

Comprehensive evaluation

Emission reduction measures

\begin{abstract}
As a pillar industry with high energy consumption and low efficiency, the building industry of China has produced consistently high carbon emission levels in recent years. The important goals in the coordinated development of this industry include the large-scale development of green buildings, the use of energy technologies to reduce carbon emissions, and an effective reduction of carbon intensity. Prefabricated buildings have become popular in this industry due to their low energy consumption, emission, and pollution and environment-friendly nature. This paper examines those factors that influence the carbon emissions from the construction of prefabricated buildings across three phases, namely, production in plants, logistics transportation, and assembly construction, builds an evaluation index system for studying the carbon emissions in the materialization phase of prefabricated buildings, and employs the hierarchical fuzzy comprehensive evaluation method to construct an evaluation model. Results show that the overall energy consumption of prefabricated buildings is lower than that of traditional concrete pouring-type buildings. The hierarchical fuzzy comprehensive evaluation model is scientific and reasonable when used to measure the comprehensive benefits of carbon emissions from prefabricated buildings. By taking a project in Zhengzhou City, Henan Province as an example, the comprehensive evaluation results show that the carbon emissions of this project are at moderate levels. The carbon emissions from prefabricated buildings can be reduced by expanding the market scale of the building industry, adjusting its use of building materials, and setting up special funds for these buildings. The findings of this work provide a certain reference value for analysing the differences between prefabricated and traditional buildings in terms of their carbon emissions in the materialization phase, for evaluating how the carbon emissions of the former can be reduced, and for formulating and executing building emission reduction plans.
\end{abstract}

\section{INTRODUCTION}

As a pillar industry in China, the building industry is related to the raw production of steel and cement at the upper end of the industrial chain and the sale of real estate at the tail end. This industry plays a critical role in promoting economic development, maintaining social stability, and driving the development of other industries. While the building industry only ranks second to the power, transportation, and manufacturing industries in terms of carbon emissions, due to its high energy consumption and low efficiency, the carbon emissions of this industry have remained at high levels in recent years. As shown in Fig. 1, the proportion of energy consumed by the building industry is continuously rising, and the total carbon emissions in China will inevitably increase along with the growth of built areas in the country. In response to these issues, the "13th Five-Year Plan of the Building Industry" issued in 2017 highlighted the importance of energy conservation, emission reduction, and low-carbon development of buildings. Along with the gradual deterioration of the environment, many issues, such as environmental pollution and energy consumption, have become important problems in all walks of life. The European Architects Association claimed that the building industry is the main contributor to global greenhouse gas (GHG) emissions, thereby highlighting the importance of studying the green and low-carbon orientations of this industry. To achieve a coordinated development, the building industry of China needs to realize a large-scale production of green buildings on the precondition of steady development, strive for low-carbon development by using energy technologies, and effectively reduce its carbon intensity.

To achieve its goal of developing a low-carbon, sustainable economy, the building industry is aiming toward low energy consumption, low emission, low pollution, and environment-friendly directions to satisfy the ever-increasing demand of humans. Low-carbon buildings are known for their low utilization of fossil energy resources, high ener- 


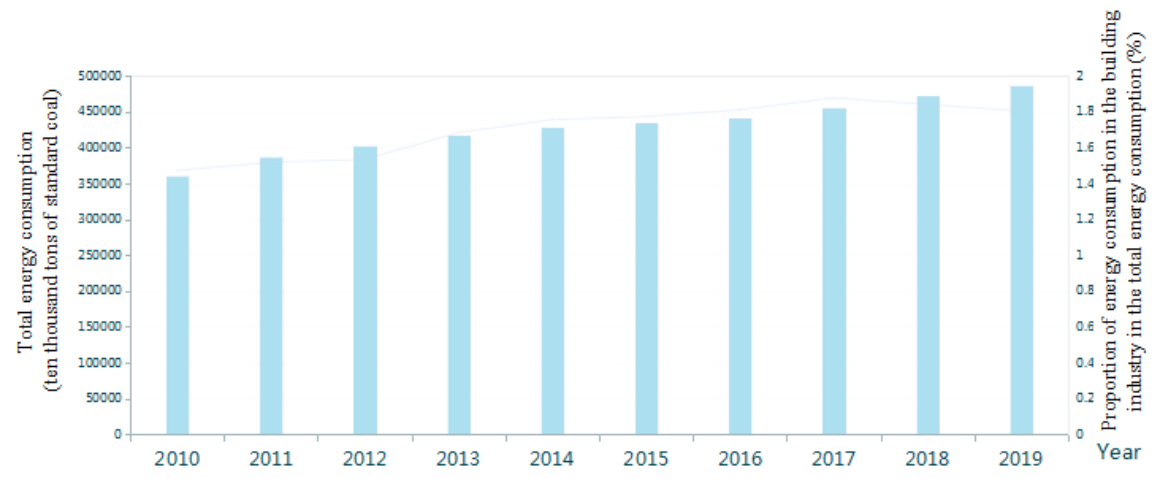

Fig. 1: Total energy consumption in China and the proportion of energy consumption of the building industry from 2010 to 2019.

gy efficiency, and zero carbon emissions throughout their whole life cycle. All or some components of prefabricated buildings are produced in a plant in advance, transported to the construction site, and assembled by using suitable installation machinery and methods. Under the industrialized production mode, prefabricated buildings have numerous advantages over traditional cast-in-place buildings, including their convenient construction, fast construction progress, negligible impacts on the environment, and low carbon emission. Therefore, these buildings play an important role in realizing a low-carbon, sustainable development of the building industry. The construction mode of these buildings also satisfies the development requirements for low-carbon buildings.

\section{PAST STUDIES}

The building industry is continuously moving toward low energy consumption, low emission, low pollution, and environment-friendly directions to satisfy the ever-increasing demand of humans. Carbon emission reduction plays an essential role in curbing GHG emissions. As prefabricated buildings produce limited carbon emissions during their materialization phase, they have become an important development trend in the building industry. Accordingly, these buildings have been subject to critical examinations in the literature. For instance, Seongwon et al. evaluated the carbon emission in the full lifecycle, materialization phase, and operation and maintenance phase of residential buildings by using the mixed evaluation, input-output, and process evaluation methods, respectively (Seongwon et al. 2001). Hens $\mathrm{H}$. et al. established a carbon emission model by using the checklist method to statistically analyze the carbon emissions of five building types and found that the envelope structure of buildings has the greatest influence on carbon emissions during the building construction and operation phase (Hens et al. 2010). Blengini \& Di Carlo et al. analysed the carbon emission and energy consumption of Japanese buildings throughout their lifecycle and calculated the resource supply for office buildings (Blengini \& Di Carlo 2010). Hu et al. constructed an overall evaluation system for low-carbon buildings that analyses the virtual energy, energy utilization efficiency, and equipment performance of buildings and argued that evaluating the carbon emissions of buildings throughout their lifecycle should cover the material production, building construction, material replacement, equipment operation, and demolition phases of these structures (Hu et al. 2011). Sivaraman constructed a refined evaluation model for studying the performance of low-carbon buildings throughout their lifecycle and identified two major factors that influence the carbon emissions of these buildings, namely, building materials and maintenance during use (Sivaraman 2011). After calculating the carbon emissions and energy consumption throughout the lifecycle of the Engineering Building of the Curtin University of Technology, Biswas. et al. found that the carbon emissions generated by this building throughout its use phase were $63 \%$ lower than that generated by other buildings (Biswas et al. 2014). Hong et al. examined the processes in the building construction phase and calculated the carbon emissions in the manufacturing, transportation, and construction phases of construction engineering materials by using the input-output and process-based methods (Hong et al. 2014). After calculating the carbon emissions of three types of buildings, Fenglai et al. analysed the limitations of the process-based and input-output methods and proposed a mixed method that integrates the characteristics of these two methods (Fenglai et al. 2016). Ciutina et al. found that the collective apartment buildings constructed in Romania by using large-scale precast concrete planks have low energy efficiency (Ciutina et al. 2016). Hong et al. found that prefabricated construction, which can effectively improve the production efficiency of the building industry, has attracted the attention of many countries and, by taking a practical building project as an example, discussed the 
energy use of prefabricated parts throughout their lifecycle. Their case results show that the recovery of prefabricated parts can save $16 \%$ to $24 \%$ of energy (Hong et al. 2016). Li et al. measured the GHG and non-GHG emissions during the building construction phase by using the process-based method (Li et al. 2017). Kou et al. established a dynamic full-life-cycle simulation model and analysed the available measures for reducing the energy consumption of residential buildings (Kou et al. 2019). Boutouil et al. eliminated the environmental impacts caused by heat treatment and concrete and further reduced the carbon footprints generated in the cement industry by using ground granulated blast furnace slag and ultrafine Portland cement (Boutouil et al. 2020). Gao et al. found that the GHG emissions in the building industry increase at an annual rate of $1.5 \%$ and used the mixed model to evaluate the environmental impacts of prefabricated and traditional cast-in-place buildings throughout their lifecycle. Their results show that prefabricated buildings have total energy consumption and carbon emission of $7.54 \%$ and $7.17 \%$ throughout their lifecycle, respectively, both of which are lower than those of traditional cast-in-place buildings (Gao et al. 2020). Kuusk et al. introduced methods and results that can facilitate the selection of thermal insulation components that are prefabricated by using complete sets of wooden frames in major house renovations and found that such schemes satisfy the energy performance requirements specified by the New Zealand Energy Bureau and reduce carbon emissions (Kuusk et al. 2020).

These studies all show that the global building industry is continuously developing toward low energy consumption, low emission, low pollution, and environment-friendly directions to satisfy the ever-increasing needs of humans. Given their ability to effectively reduce the consumption of resources and energy sources and produce minimal waste on construction sites, prefabricated buildings have become the mainstream development trend in the building industry. However, China lags behind developed countries in terms of developing prefabricated buildings due to a series of difficulties related to costs, technologies, evaluation standards, and management. Therefore, an evaluation index system was constructed in this paper to analyze those factors that influence the carbon emissions of prefabricated buildings across three phases, namely, production in plants, logistics transportation, and assembly construction. An evaluation model was also constructed by using the hierarchical fuzzy comprehensive evaluation method, the differences between prefabricated and traditional buildings were analysed, and the emission reduction of the former was evaluated. The findings of this work are expected to provide a basis for formulating effective building emission reduction plans.

\section{BRIEF INTRODUCTION TO THE MODEL}

\section{Evaluation Indexes}

Carbon emission indexes should be set in consideration of various carbon sources and factors that influence carbon emissions. These indexes should also be able to reflect the utilized resources and energy sources and the waste generated during the construction of prefabricated buildings. The setting of these indexes should also follow the principles of pollution prevention, easy quantification and measurement, scientificity, and dynamics. From the perspectives of energy conservation, emission reduction, environmental protection, and resource-saving and in reference to the assessment standards for green and prefabricated buildings, an evaluation index system was formulated in this paper as summarized in Table 1.

Table 1: Evaluation of the index system for the carbon emissions of prefabricated buildings.

\begin{tabular}{|lll|}
\hline Level I index & Level II index & Level III index \\
\hline $\begin{array}{l}\text { Utilization of resources and energy } \\
\text { sources }\left(\mathrm{B}_{1}\right)\end{array}$ & Investment amount $\left(C_{1}\right)$ & Investment amount $\left(D_{1}\right)$ \\
& Resource consumption $\left(C_{2}\right)$ & Material utilization amount $\left(D_{2}\right)$ \\
& Energy consumption $\left(C_{3}\right)$ & Coal $\left(D_{3}\right)$ \\
& & Diesel oil $\left(D_{4}\right)$ \\
& & Gasoline $\left(D_{5}\right)$ \\
Construction and ecological envi- & Environmental protection degree of construction & Personnel organization $\left(D_{6}\right)$ \\
& organization $\left(C_{4}\right)$ & Utilization of new technologies and new processes $\left(D_{7}\right)$ \\
& & Utilization of advanced construction machinery $\left(D_{8}\right)$ \\
& & Design and management of construction organization $\left(D_{9}\right)$ \\
& Waste $\left(C_{5}\right)$ & Amount of construction wastes $\left(D_{10}\right)$ \\
& & Construction waste recycling $\left(D_{11}\right)$ \\
& Implementation degree of environmental policies $\left(C_{6}\right)$ & Implementation of national construction standard $\left(D_{12}\right)$ \\
\hline
\end{tabular}


Model Profile

Establishment of a fuzzy factor set: First, the influence factor set, namely, the comprehensive evaluation factor set $U$, was constructed as

$$
U=\left\{u_{1}, u_{2}, u_{3} \cdots u_{n}\right\}
$$

Where $u_{i}=(i=, 2, \ldots, n)$ represents the influence factors. The 12 factors in Tab. 1 were chosen to form an evaluation factor set for the carbon emissions of prefabricated buildings.

Establishment of a comprehensive evaluation set: The single-factor fuzzy evaluation, that is, the problem analysis of a specific factor serves as the basis of a comprehensive evaluation. Single-factor fuzzy evaluation is generally realized through investigation followed by the construction of a comprehensive evaluation set and a combination of possible evaluation results given by the evaluator for the evaluation objects.

Weight determination: The analytic hierarchy process (AHP) was used to calculate the weight of each index as $W_{\mathrm{i}}$.

$$
W=\left(w_{1}, w_{2}, \cdots, w_{i}\right), 0 \leq w_{i} \leq 1, \sum_{i=1}^{n} w_{i}=1
$$

where $w_{i}$ denotes the index weight calculated via AHP.

Fuzzy comprehensive evaluation based on AHP: By using the fuzzy comprehensive evaluation method based on AHP, the first-grade judgment matrix was formed as:

$$
C_{i}=W_{c i} \times R_{c i}
$$

Where $C_{i}$ is the first-grade comprehensive membership. Afterwards, the second-grade judgment matrix was constructed as:

$$
B_{i}=W_{B i} \times \mathrm{R}_{\mathrm{Bi}}
$$

Where $R_{B 1}=\left[\begin{array}{lll}C_{1} & C_{2} & C_{3}\end{array}\right]^{T}, R_{B 2}=\left[\begin{array}{lll}C_{4} & C_{5} & C_{6}\end{array}\right]^{T}$. In the end, the third-grade judgment matrix was formed as:

$$
A=W \times R, R=\left[B_{1} B_{2}\right]^{T},
$$

Where $A$ is the fuzzy comprehensive evaluation result for the carbon emission of prefabricated buildings.

Case analysis: The project case was located in Zhengzhou City, Henan Province. The project site was featured by an overall open terrain and convenient transportation that facilitated the transportation of building materials and mechanical equipment. The prefabricated construction was integrated with the traditional cast-in-place construction in this project. Specifically, the related components were produced in a plant in advance followed by their field installation. The investment amount was calculated by the construction cost per square meter of the building. According to the Settlement Document and Material List from the factory for prefabrication, the material consumption was calculated by using related data obtained from the investigation, whereas the mechanical energy consumption was derived from the energy consumed during the processing of components in the plant, the energy consumed during transportation, and the energy consumed during site construction. The components in this project were produced in the plant by means of standard and information-based management, which not only improved the standard and quality of the components but also effectively enhanced their production efficiency. As for their installation, the components and construction machinery were reasonably arranged to avoid unnecessary rehandling within the construction site and block carbon emissions during the transportation process. The wastes of

Table 2: Weight table of the evaluation index.

\begin{tabular}{|llllll|}
\hline Level I index & Weight & Level II index & Weight & Level III index & Weight \\
\hline $\mathrm{B}_{1}$ & 0.65 & $C_{1}$ & 0.28 & $\mathrm{D}_{1}$ & 1 \\
& $C_{2}$ & 0.13 & $\mathrm{D}_{2}$ & 1 \\
& $C_{3}$ & 0.59 & $\mathrm{D}_{3}$ & 0.33 \\
& & & $\mathrm{D}_{4}$ & 0.14 \\
& & & $\mathrm{D}_{5}$ & 0.53 \\
$\mathrm{~B}_{2}$ & $C_{4}$ & 0.31 & $\mathrm{D}_{6}$ & 0.17 \\
& & & $\mathrm{D}_{7}$ & 0.33 \\
& & & $\mathrm{D}_{8}$ & 0.33 \\
& & & $\mathrm{D}_{9}$ & 0.17 \\
& & & $\mathrm{D}_{10}$ & 0.75 \\
& & 0.11 & $\mathrm{D}_{11}$ & 0.25 \\
& $C_{5}$ & & $\mathrm{D}_{12}$ & 1 \\
\hline
\end{tabular}


the prefabricated buildings in this project mainly included concrete, insulation boards, mortars, steels, and timbers. The timbers, which were mainly timber formworks, were uniformly classified and were not stacked together with other solid wastes. The wastes generated by the prefabricated building construction were reduced, the steel materials were recycled on the site, and other materials, such as concrete, insulation boards, and mortars, were almost not reused.

Nine experts in profound studies of prefabricated buildings were invited to score the index system, and the weight table (Table 2) was obtained through the calculation.

The scores of level I indexes were calculated according to formulas (2) to (5).

$$
\begin{aligned}
& B_{1}=\left[\begin{array}{lll}
0.28 & 0.13 & 0.59
\end{array}\right] \cdot\left[\begin{array}{ccc}
1 & 0 & 0 \\
0 & 0 & 1 \\
0 & 0.53 & 0.47
\end{array}\right]=\left[\begin{array}{lll}
0.28 & 0.31 & 0.41
\end{array}\right] \\
& B_{2}=\left[\begin{array}{lll}
0.28 & 0.31 & 0.41
\end{array}\right] \cdot\left[\begin{array}{ccc}
0.33 & 0.34 & 0.33 \\
0.25 & 0.75 & 0 \\
1 & 0 & 0
\end{array}\right]=\left[\begin{array}{lll}
0.58 & 0.33 & 0.09
\end{array}\right]
\end{aligned}
$$

Through a second-grade judgment, the comprehensive scores of resource and energy utilization, construction organization, and ecological environment were obtained. According to the maximum membership principle, the comprehensive score of carbon emission from resources and energy sources was 0.41 , whereas that from construction and the ecological environment was 0.58 . The third-grade judgment, which refers to the highest index level and layer, was used to obtain the comprehensive evaluation result for the carbon emissions of prefabricated buildings.

$$
A=W \cdot R \cdot\left[\begin{array}{ll}
B_{1} & B_{2}
\end{array}\right]^{T}=\left[\begin{array}{ll}
0.41 & 0.58
\end{array}\right] \cdot\left[\begin{array}{ll}
0.280 .31 & 041 \\
0.580 .33 & 0.09
\end{array}\right]=\left[\begin{array}{lll}
0.45 & 0.32 & 0.22
\end{array}\right]
$$

According to the maximum membership principle, the evaluation score for the carbon emission of prefabricated buildings was 0.45 . Based on its evaluation result, the project case in Zhengzhou City, Henan Province had a moderate level of carbon emissions.

\section{POLICY SUGGESTIONS}

\section{Expand the Market Scale of the Building Industry and Boost Market Competition}

Increasingly fierce market competition can be observed in the building industry. To survive and seek long-term development amid this competition, the related industries should engage in low-carbon technological innovation. Therefore, construction enterprises should be guided to expand their market scale and enhance market competition, which will encourage them to carry out low-carbon technological innovation activities to improve their competitiveness. The market demand should also be increased, enterprise innovation should be guided, and construction enterprises should develop low-carbon products by increasing the consumer demand for these products. Certain subsidies can be provided to consumers who purchase low-carbon products, the related product purchase taxes should be reduced, and incidental services of low-carbon products can be reinforced.

\section{Adjust the Utilization of Building Materials and Strengthen the Technological Innovation}

Among the total carbon emissions of the building industry, those generated by the consumption of building materials, particularly cement and steel, account for a large proportion. Moreover, the high energy consumption and carbon emissions of building materials are direct causes of extremely high levels of carbon emission intensity. Therefore, the technological innovation level in the production of building materials should be increased, and construction enterprises should be encouraged to promote new types of energy-saving and renewable building materials and increase the proportion of high-intensity and high-performance building materials that they use. Their construction processes should also be optimized, their building materials should be recycled, and the amount of building materials they use should be reduced. The construction and utilization of prefabricated buildings should also be strengthened, and the development of intelligent and integrated buildings should be promoted.

\section{Set up Special Funds for Prefabricated Buildings and Provide Tax Preferences}

Setting up special funds for the development of prefabricated buildings can increase the development and construction area of these buildings. In the initial development phase of these buildings, high costs are among the primary factors that restrict related R\&D works. Setting up special funds can also promote the development of human resources, energy sources, and equipment, encourage innovations in production and construction technologies, and effectively monitor and manage information-based projects. In view of the current development status of prefabricated buildings in China, tax preferences should be continuously improved. Preferential policies in income and value-added taxes should be provided to component manufacturers and enterprises specializing in the development and construction of prefabricated buildings. The corresponding directory and detailed preferences for the production and use of building materials should be refined to motivate initiatives in the building industry. 


\section{Strengthen the Monitoring of Prefabricated Construction and Reduce the Discharge of Pollutants}

Several factors should be considered when optimizing a logistics transportation plan, including transportation time, transportation mode, transportation route, and component loading plan. Logistics transportation can be optimized only based on a comprehensive analysis of the aforementioned influencing factors. Unnecessary secondary logistics transportation should be avoided as much as possible, and the usage of clean energy vehicles should be promoted. Resources and energy sources, such as water, electricity, and other materials, can be conserved by using advanced construction machinery. Turnover can be increased by saving materials on construction sites. To realize scientific management, the building materials should be saved as much as possible, and their waste should be reduced to the maximum extent. A scientific and reasonable arrangement of work implementation and operations should be formulated prior to the construction and early-stage prevention works to reduce the generation of construction waste and to increase material recycling efficiency. Land should be conserved to the highest degree, the stacking of building materials should be well controlled, and stacking and transportation schemes should be optimized to reduce unnecessary secondary transportation.

\section{CONCLUSION}

Aiming toward a low-carbon, sustainable economy, the building industry has shifted its development direction toward low energy consumption, low emission, low pollution, and environment-friendly directions to satisfy the ever-increasing demands of humans. Under the industrialized production mode, prefabricated buildings demonstrate various advantages over traditional cast-in-place buildings, such as their convenient and fast construction, negligible effects on the environment, and low carbon emissions. Accordingly, prefabricated construction has become an important path to realize the low-carbon and sustainable development of the building industry. Prefabricated construction also conforms to the development requirements for low-carbon buildings. Those factors that influence prefabricated buildings across three phases, namely, production in plants, logistics transportation, and assembly construction, were analysed in this paper. An evaluation index system for evaluating the carbon emissions of prefabricated buildings during their materialization phase was constructed, and an evaluation model was built by using the hierarchical fuzzy comprehensive evaluation method. Results show that the hierarchical fuzzy comprehensive evaluation model is scientific and reasonable for measuring the comprehensive carbon emission benefits of prefabricated buildings. A comprehensive evaluation of a project in Zhengzhou City, Henan Province reveals that this project had a moderate level of carbon emissions. Several emission reduction measures were also proposed, including expanding the market scale of the building industry, adjusting the use of building materials, setting up special funds for prefabricated buildings, and strengthening the monitoring of prefabricated construction. The differences between prefabricated and traditional buildings in terms of their social comprehensive benefits can be explored in depth in future studies, and a carbon emission factor database and carbon emission standard for prefabricated buildings should also be established.

\section{REFERENCES}

Blengini, G.A. and Di Carlo, T. 2010. The changing role of life cycle phases, subsystems and materials in the LCA of low energy buildings. Energy and Buildings, 42(6): 869-880.

Boutouil, M. and Sebaibi N. 2020. Reducing energy consumption of prefabricated building elements and lowering the environmental impact of concrete. Engineering Structures, 213: 110594.

Biswas, Wahidul K. 2014. Carbon footprint and embodied energy consumption assessment of building construction works in Western Australia. International Journal of Sustainable Built Environment, 3(2): 179-186.

Ciutina, A., Floricel, A., Ungureanu, V. and Zagari, G. 2016. Structural solutions based on intensive use of steel for over-roofing of existing precast concrete panel buildings. Advances in Structural Engineering, 19(12): 1940-1948.

Fenglai, Xiaocun, Wang, Zhang. 2016. Assessment of embodied carbon emissions for building construction in China: Comparative case studies using alternative methods. Energy \& Buildings, 130: 330-340.

Gao, W., Kuroki, S., Wang, H. and Zhang, Y. 2020. Life cycle environmental and cost performance of prefabricated buildings. Sustainability, 12.

Hong, T., Ji, C. Y., Jang, M. H. and Park, H.S. 2014. Assessment model for energy consumption and greenhouse gas emissions during building construction. Journal of Management in Engineering, 30(2): 226-235.

Hong, J., Li, K., Li, Z., Mao, C. and Shen, G. Q. 2016. Life-cycle energy analysis of prefabricated building components: An input-output-based hybrid model. Journal of Cleaner Production, 112: 2198-2207.

Hens, H. and Verbeeck, G. 2010. Life cycle inventory of buildings: A calculation method. Building \& Environment, 45(4): 1037-1041.

Hu, D., Wang, B., You, F., Ye, Y., Zhang, G., Zhen, H. and Zhao, Y. 2011. Carbon emissions in the life cycle of urban building system in China-A case study of residential buildings. Ecological Complexity, 8(2): 201-212.

Kuusk, K., Kalamees, T. and Pihelo, P. 2020. Development and performance assessment of prefabricated insulation elements for deep energy renovation of apartment buildings. Energies, 13.

Kou, C., Li, G. and Wang H. 2019. Estimating city-level energy consumption of residential buildings: A life-cycle dynamic simulation model. Journal of Environmental Management, 240(15): 451-462.

Li, C., Luo, W., Sandanayake, M., Setunge, S. and Zhang, G. 2017. Estimation and comparison of environmental emissions and impacts at foundation and structure construction stages of a building-A case study. Journal of Cleaner Production, 151(May 10): 319-329.

Sivaraman, D. 2011. An integrated life cycle assessment model: Energy and greenhouse gas performance of residential heritage buildings, and the influence of retrofit strategies in the state of Victoria in Australia. Energy \& Buildings, (5): 29-35.

Seongwon, S. and Yongwoo, H. 2001. Estimation of $\mathrm{CO}_{2}$ Emissions in life cycle of residential buildings. Journal of Construction Engineering \& Management,127(5): 414-418. 